\title{
Genetic Inactivation of the NMDA Receptor NR2A Subunit has Anxiolytic- and Antidepressant-Like Effects in Mice
}

\author{
Janel M Boyce-Rustay*,' and Andrew Holmes' \\ 'Section on Behavioral Science and Genetics, Laboratory for Integrative Neuroscience, National Institute on Alcohol Abuse and Alcoholism, \\ National Institutes of Health, Rockville, MD, USA
}

\begin{abstract}
There is growing evidence implicating the glutamate system in the pathophysiology and treatment of mood and anxiety disorders. Glutamatergic neurotransmission is mediated by several receptor subfamilies including multiple NMDA receptor subunits (NR2A-D). However, little is currently understood about the specific roles of NMDA subunits in the mediation of emotional behavior due to a lack of subunit-specific ligands. In the present study, we employed a mouse gene-targeting approach to examine the role of the NR2A subunit in the mediation of anxiety- and depressive-related behaviors. Results showed that NR2A knockout (KO) mice exhibit decreased anxiety-like behavior relative to wild-type littermates (WT) across multiple tests (elevated plus maze, light-dark exploration test, novel open field). NR2A KO mice showed antidepressant-like profiles in the forced swim test and tail suspension test, as compared to WT controls. Locomotor activity in the nonaversive environments of the home cage or a familiar open field were normal in the NR2A KO mice, as were gross neurological and sensory functions, including prepulse inhibition of startle. Taken together, these data demonstrate a selective and robust reduction in anxiety- and depression-related behavior in NMDA receptor NR2A subunit KO mice. Present results support a role for the NR2A subunit in the modulation of emotional behaviors in rodents and provide insight into the role of glutamate in the pathophysiology and treatment of mood and anxiety disorders.

Neuropsychopharmacology (2006) 3 I, 2405-24I4. doi:I0.1038/sj.npp. I30 I039; published online 8 February 2006
\end{abstract}

Keywords: NMDA; NR2A; glutamate; anxiety; depression; knockout

\section{INTRODUCTION}

There is growing evidence in support of an important role for the glutamate system in the mediation of emotion, and in the pathophysiology of mood and anxiety disorders. Some but not all studies have found altered levels of glutamate and glutamate receptor binding in the brains of depressed patients and suicide victims (Auer et al, 2000; Holemans et al, 1993; Law and Deakin, 2001; MeadorWoodruff et al, 2001; Nowak et al, 1995; Palmer et al, 1994; Pfleiderer et al, 2003). In rodents, exposure to stress produces a robust increase in glutamate release in regions mediating emotional behavior, such as the locus coeruleus, hippocampus and prefrontal cortex (Moghaddam, 1993; Moghaddam et al, 1994; Singewald et al, 1995, 1996). Additionally, exposure to stress increases NMDA receptor

\footnotetext{
*Correspondence: Dr JM Boyce-Rustay, Section on Behavioral Science and Genetics, Laboratory for Integrative Neuroscience, National Institute on Alcohol Abuse and Alcoholism, 5625 Fishers Lane Rm 2N-09, Rockville, MD 20892, USA, Tel: + I 301443 4052, Fax: + I 30 I 480 1952, E-mail: boycej@mail.nih.gov

Received 16 September 2005; revised II December 2005; accepted 20 December 2005

Online publication: 4 January 2006 at http://www.acnp.org/citations/ Npp0 040605058 I/default.pdf
}

expression and mRNA levels in the rat ventral tegmental area and hippocampus (Bartanusz et al, 1995; Fitzgerald et al, 1996).

While these data point to glutamatergic involvement in emotional regulation, defining this role is difficult because glutamate exerts its effects on neural function in a highly complex manner. Glutamatergic neurotransmission is mediated via ionotropic ( $N$-methyl-D-aspartate (NMDA), L-alpha-amino-3-hydroxy-5-methylisoxazole-4-propionat (AMPA), kainate) and metabotropic receptors. However, possible differential functional roles of these receptor subfamilies in the mediation of behavioral processes such as emotion remains incompletely understood. Recent studies in rodents have demonstrated that blockade of glutamate's actions at metabotropic and AMPA receptors exerts antidepressant-like and anxiolytic-like effects in various tasks, leading to the clinical development of metabotropic glutamate receptors for emotional disorders (for reviews, see (Javitt, 2004; Spooren and Gasparini, 2004; Swanson et al, 2005)). Manipulation of NMDA receptor function has also been found to affect emotion-related behaviors in rodent models. In rats, treatment with competitive NMDA receptor antagonists produces anxiolytic- and antidepressant-like effects in various tasks, such as the elevated plus-maze and forced swim test, at doses that 
do not produce nonspecific changes in locomotor activity (Martinez et al, 2002; Molchanov and Guimaraes, 2002; Przegalinski et al, 2000; Trullas and Skolnick, 1990; Wiley et al, 1995). Moreover, some but not all, noncompetitive NMDA receptor channel blockers exert anxiolytic- and antidepressant-like effects in these models (Silvestre et al, 1997; Wiley et al, 1995).

While these findings suggest NMDA receptor modulation of emotional behaviors, it remains unclear whether these effects result from antagonism of specific NMDA receptor subunits. NMDA receptors are tetramers composed of two NR1 and two NR2 (NR2A-NR2D) subunits (Laube et al, 1998; Rosenmund et al, 1998; Schorge and Colquhoun, 2003). The NR2 subunit present in a functional NMDA receptor determines the physiological characteristics of the NMDA receptor; for example, NMDA receptors containing NR2A mediate faster neurotransmission than NR2B-containing NMDA receptors (Cull-Candy et al, 2001). In addition, NR2A and NR2B subunits are differentially expressed over the course of development, with NR2B predominating in the mouse brain until the end of the second postnatal week (Liu et al, 2004b). In the adult mouse brain, NR2A- and NR2B-containing NMDA receptors are both highly expressed in brain regions implicated in emotion (Law et al, 2003; Magnusson et al, 2002; Sah and Lopez De Armentia, 2003). Determining the differential roles for specific subunit-containing receptors in behavior is hampered by the lack of NR2A subunit selective pharmacological ligands. In this context, gene-targeting in mice provides a valuable approach to studying the molecular basis of emotional behavior (Holmes, 2001; Holmes et al, 2003a, b, c), and the behavioral functions of NMDA subunits (Boyce-Rustay and Holmes, 2005; Tang et al, 1999; Tsien et al, 1996).

In the current study, we used a mouse model in which the gene encoding the NR2A subunit (Grin $2 a$ ) was functionally inactivated to investigate the role of NR2A in regulating emotional behavior. Homozygous NR2A null mutant ('knockout,' KO) and heterozygous mutant (HET) mice were compared to wild-type (WT) littermate controls on a battery of tests for anxiety-related behaviors (elevated plus maze, light/dark exploration test, novel open field) and depression-related behaviors (forced swim test, tail suspension test). To control for nonspecific phenotypic alterations that could confound interpretation of anxiety- and depression-related behaviors in NR2A KO mice, such as motoric abnormalities (Holmes and Cryan, 2005), NR2A KO mice were assessed for locomotor activity in nonaversive environments (home cage, familiar open field) and examined on a screen for gross behavior, neurological and sensory functions (Crawley and Paylor, 1997; Holmes et al, 2001).

\section{MATERIALS AND METHODS}

\section{Subjects}

NR2A KO mice were generated as previously described (Sakimura et al, 1995; Watanabe et al, 1993). Briefly, the targeting vector (pTVGR $\varepsilon 1$ ) was a $1.3 \mathrm{~kb}$ blunted EcoRIBamHI fragment containing the neomycin phosphotransferase gene under the control of the phosphoglycerate kinase promoter. This was then inserted into the $X \mathrm{cml}$ site of the $10.0 \mathrm{~kb}$ GluR $\varepsilon 1$ DNA from a C57BL/6 genomic library and a synthetic adaptor carrying Sa/I, HindIII and SmaI sites replaced NotI-Xhol segment $(16.5 \mathrm{~kb})$ located between the ClaI and SacI sites. DNA was digested with NotI. TT2. C57BL/6 $\times$ CBA F1 hybrid ES cells were cultured, selected, and the target clones were identified by G418 selection, PCR and South blot hybridization. Embryonic stem cell clones were microinjected into ICR blastocysts to obtain chimeric progeny. Chimeric males were mated to C57BL/6 female mice. Offspring were genotyped by Southern blot analysis of tail biopsies to confirm germline transmission.

For the current study the NR2A null mutation was backcrossed into the C57BL/6J strain for $>10$ generations to produce a congenic $\mathrm{C} 57 \mathrm{BL} / 6 \mathrm{~J}$ genetic background. Analysis of 150 SNP markers at 15-20 megabase intervals across all autosomal chromosomes confirmed $>99 \%$ C57BL/6J congenicty in the mutant line (JRS Allele Typing Services, The Jackson Laboratory, Bar Harbor, ME, USA). To avoid potential phenotypic abnormalities resulting from genotypic differences in maternal behavior and early life environment, NR2A KO, NR2A HET and WT mice were all generated from HET $\times$ HET matings. Mice were bred and maintained at The Jackson Laboratory (Bar Harbor, ME, USA) and shipped to the NIH at 7-9 weeks of age and testing began at a minimum of 10 weeks of age. On arrival at $\mathrm{NIH}$, mice were housed in groups of 2-4 with same-sex littermates in a temperature and humidity controlled vivarium under a $12 \mathrm{~h}$ light/dark cycle (lights on $06: 00)$.

\section{Behavioral Testing}

Testing was conducted using five separate cohorts of mice. One cohort (11 male WT, three female WT, 12 male HET, six female HET, seven male $\mathrm{KO}$, seven female $\mathrm{KO}$ ) was evaluated for physical heath, sensory and neurological functions, and then tested on the novel open field, elevated plus maze, light-dark exploration, and tail suspension test, in that order, with at least 1 week between tests. A second cohort (second male WT, four female WT, two male HET, four female $\mathrm{HET}$, two male $\mathrm{KO}$, one female $\mathrm{KO}$ ) was tested on the forced swim test. A third cohort (six male WT, four female WT, six male HET, six female HET, six male KO, six female KO) was tested on the forced swim test and home cage activity with $>10$ weeks between experiments. A fourth cohort (six male WT, six female WT, seven male HET, eight female HET, 11 male KO, four female KO) was tested for acoustic startle and prepulse inhibition of the startle response. A fifth cohort (four male WT, four female WT, six male HET, five female HET, six male KO, three female KO) was tested on the repeated open field test. With the exception of the home activity, all testing was conducted during the light phase of the light/dark cycle. Where appropriate, apparatuses were cleaned between subjects with a $70 \%$ ethanol $(\mathrm{v} / \mathrm{v})$ solution. The experimenter remained blind to genotype during testing; animals were identified by subcutaneously implanted microchips. All experimental procedures were approved by the National Institute on Alcohol Abuse and Alcoholism Animal Care and Use Committee and strictly followed the NIH guidelines 'Using Animals in Intramural Research'. 


\section{Tests for Anxiety-Related Behaviors}

Elevated plus-maze. The elevated plus-maze test was conducted as previously described (Handley and Mithani, 1984; Holmes et al, 2003a, c). The apparatus consisted of two open arms $(30 \times 5 \mathrm{~cm} ; 90$ lux $)$ and two closed arms $(30 \times 5 \times 15 \mathrm{~cm} ; 20 \mathrm{lux})$ extending from a $5 \times 5 \mathrm{~cm}$ central area and elevated $20 \mathrm{~cm}$ from the ground (San Diego Instruments, San Diego, CA, USA). The walls were made from black ABS plastic and the floor from white ABS plastic. A $0.5 \mathrm{~cm}$ raised lip around the perimeter of the open arms prevented mice from falling off the maze. The mouse was placed in the center facing an open arm and allowed to explore the apparatus for $5 \mathrm{~min}$. Time spent in the open arms, and entries into the open and closed arms were measured by the Ethovision videotracking system (Noldus Information Technology Inc., Leesburg, VA, USA).

Light-dark exploration test. The light-dark exploration test was conducted as previously described (Crawley, 1981; Holmes et al, 2003a, c). The apparatus consisted of two compartments (each $17 \times 13 \times 13 \mathrm{~cm}$ ), one with white Plexiglas walls and clear Plexiglas floor (40 lux) ('light' compartment) and the other with black Plexiglas walls and clear Plexiglas floor (0 lux) ('dark' compartment) that were connected by a partition at floor level with a small opening $(5 \mathrm{~cm}$ ) (Med Associates, Georgia, VT, USA, Model ENV3013). The mouse was placed into the dark compartment facing away from the aperture and allowed to explore the apparatus for $10 \mathrm{~min}$. Time spent and full-body transitions into the light compartment, and total full-body transitions between the light and dark compartments were measured by photocells connected to Med Associates software.

Novel and familiar open field tests. The novel open field test was conducted as previously described (Holmes et al, $2003 \mathrm{a}, \mathrm{c})$. The apparatus was a $40 \times 40 \times 35 \mathrm{~cm}$ square arena (50lux) constructed of white Plexiglas. The mouse was placed in the perimeter and allowed to explore the apparatus for $60 \mathrm{~min}$. Total distance traveled in the whole arena and time spent in the center $(20 \times 20 \mathrm{~cm})$ was measured by the Ethovision videotracking system (Noldus Information Technology Inc., Leesburg, VA, USA).

In a separate experiment to compare responses to a novel $v s$ familiar open field, open field-naive mice were exposed to the open field for 30 min per day on 5 consecutive days, using the same apparatus and procedure as described above.

Home cage locomotor activity. Home cage activity was measured to assess locomotor behavior in a non-aversive environment, as described previously (Holmes et al, 2002a). Mice were individually housed in a standard home cage under normal vivarium conditions and left undisturbed for a $48 \mathrm{~h}$ acclimation period. Home cage activity was then measured over $24 \mathrm{~h}$ using the photocell-based Opto M3 activity monitor (Columbus Instruments, Columbus, OH, USA).

\section{Tests for Depression-Related Behaviors}

Forced swim test. The forced swim test was conducted as previously described (Holmes et al, 2002b; Porsolt et al,
1978). The apparatus was a transparent Plexiglas cylinder $\left(20 \mathrm{~cm}\right.$ diameter) filled halfway with water $\left(24 \pm 1^{\circ} \mathrm{C}\right)$. The mouse was gently lowered into the water and manually observed for the presence/absence of immobility (cessation of limb movements except minor involuntary movements of the hind limbs) every $5 \mathrm{~s}$ during the last $8 \mathrm{~min}$ of a $10 \mathrm{~min}$ test session.

Tail suspension test. The tail suspension test was conducted as previously described (Holmes et al, 2002b; Steru et al, 1985). The mouse was securely fastened by the end of the tail to a flat surface that was suspended in a visually isolated white Plexiglas box $\left(40 \mathrm{~cm}^{3}\right)$ and manually observed for the presence/absence of immobility (cessation of limb movements) every $5 \mathrm{~s}$ during the last $4 \mathrm{~min}$ of a $6 \mathrm{~min}$ session.

\section{Evaluation of Empty Cage Behaviors, Physical Health, Sensory, and Neurological Functions}

Mice were evaluated for empty cage behaviors, physical health, sensory and neurological functions using methods based on those described previously (Crawley and Paylor, 1997; Holmes et al, 2001). Mice were first placed in a bare empty home cage and observed for the presence of freezing, trembling, sniffing, licking, rearing, jumping, spontaneous seizure, defecation, urination, head bobbing, circling, abnormal gait, and retropulsion over $60 \mathrm{~s}$. Basic physical health was then evaluated by examining for missing whiskers, bald patches, exophthalmus, straub tail, kinked tail, kyphosis, lordosis, body weight and core body temperature. Simple sensory reflexes were measured via orienting responses to an approaching hand and to physical touch, and via palpebral closure on touch of the eye, twitch of the pinna on touch and an orienting response to tail pinch. Basic motor and neurological function was assessed by observing for splayed limbs, forepaw clutch and hind limb clutch when mice were suspended upside down by the tail.

Mice were assessed for acoustic startle and prepulse inhibition of the startle response as previously described (Holmes et al, 2001) using 4 SR-Lab System startle chambers (San Diego Instruments, San Diego, CA, USA). Mice were placed into clear Plexiglas cylinders for a $5 \mathrm{~min}$ acclimation period. A $65 \mathrm{~dB}$ broadband background noise was presented during acclimation and throughout the test session. During the test session, mice were presented with startle trials (40-msec $120-\mathrm{dB}$ broadband sound pulse) and prepulse + startle trials (20-ms noise prepulse sound followed, $100 \mathrm{~ms}$ later, by a $40-\mathrm{msec} 120-\mathrm{dB}$ broadband sound pulse). The prepulse + startle trials were preceded and followed by five pulse alone trials, which were not included in the analyses. Test trials consisted of 10 trials of three different intensities (3, 6 and $12 \mathrm{~dB}$ above background). Each trial type was presented 10 times with a variable interval of 12-30 s between each presentation. Basal activity in the startle chambers was measured during no-stimulus trials. Startle amplitude was measured every $1 \mathrm{~ms}$, over a $65 \mathrm{~ms}$ period beginning at the onset of the startle stimulus. The peak startle amplitude over the sampling period was taken as the dependent variable. Whole-body startle responses were measured via vibrations transduced into 
analog signals by a piezoelectric unit attached to the platform on which the cylinders rested. Prepulse inhibition of startle was calculated as $100-(($ startle response for prepulse + startle trials/startle response for startle-alone trials) $\times 100$ )

\section{Statistical Analysis}

Analysis of all data using sex as a factor found no genotype $\times$ sex interactions; therefore data were collapsed across sex. Genotype effects were analyzed by use of analysis of variance (ANOVA) and Neuman-Keuls post hoc tests where appropriate. The effects of genotype and time (novel open field test), and genotype and trial (novel $v s$ familiar open field test), on locomotor activity in the open field were measured by use of a 2-factor ANOVA, with repeated measures for time and trial, respectively, followed by Neuman-Keuls post hoc tests. Analyses were conducted using StatView (SAS Institute Inc., Cary, NC, USA). Statistical significance was set at $P<0.05$.

\section{RESULTS}

\section{Reduced Anxiety-Like Behavior in the Elevated Plus-Maze}

There was a significant effect of genotype on measures of anxiety-related behavior, but not general locomotor activity, in the elevated plus-maze. As shown in Figure 1, NR2A KO, but not HET, mice spent significantly more time (main effect of genotype: $F_{2,43}=7.30, P<0.01$ ) and made significantly more entries into the open arms (main effect of genotype: $\mathrm{F}_{2,43}=6.01, P<0.01$ ) as compared to WT controls. There were no genotype differences in the number of closed arm entries $(P>0.05)$.

\section{Reduced Anxiety-Like Behavior in the Light-Dark Exploration Test}

Genotype significantly affected measures of anxiety-related behavior in the light/dark exploration test. NR2A KO, but not HET, mice spent significantly more time (main effect of genotype: $\mathrm{F}_{2,43}=6.82, P<0.01$ ) and made significantly more entries (main effect of genotype: $\mathrm{F}_{2,43}=6.39, P<0.01$ ) into the light compartment as compared to WT controls (Figures $2 \mathrm{a}$ and $\mathrm{b}$ ). NR2A KO mice also made significantly more light-dark transitions (main effect of genotype: $\mathrm{F}_{2,43}=6.37$; $P<0.01$ ) as compared to WT controls (Figure 2c).

\section{Reduced Anxiety-Like Behavior in the Novel Open Field Test}

There was a significant effect of genotype on behavior in the novel open field. Results in Figure 3 show that NR2A KO, but not HET, mice traveled a significantly greater distance than WT controls overall (main effect of genotype: $\left.\mathrm{F}_{2,473}=12.26 ; P<0.01\right)$. All genotypes showed differential rates of locomotor habituation over the course of the $60 \mathrm{~min}$ test session (main effect of time: $\mathrm{F}_{11,473}=70.49, P<0.01$; genotype $\times$ time interaction: $\left.\mathrm{F}_{22,473}=3.58, P<0.01\right)$. Post hoc analysis revealed that NR2A $\mathrm{KO}$ mice exhibited increased levels of locomotor activity during the start of
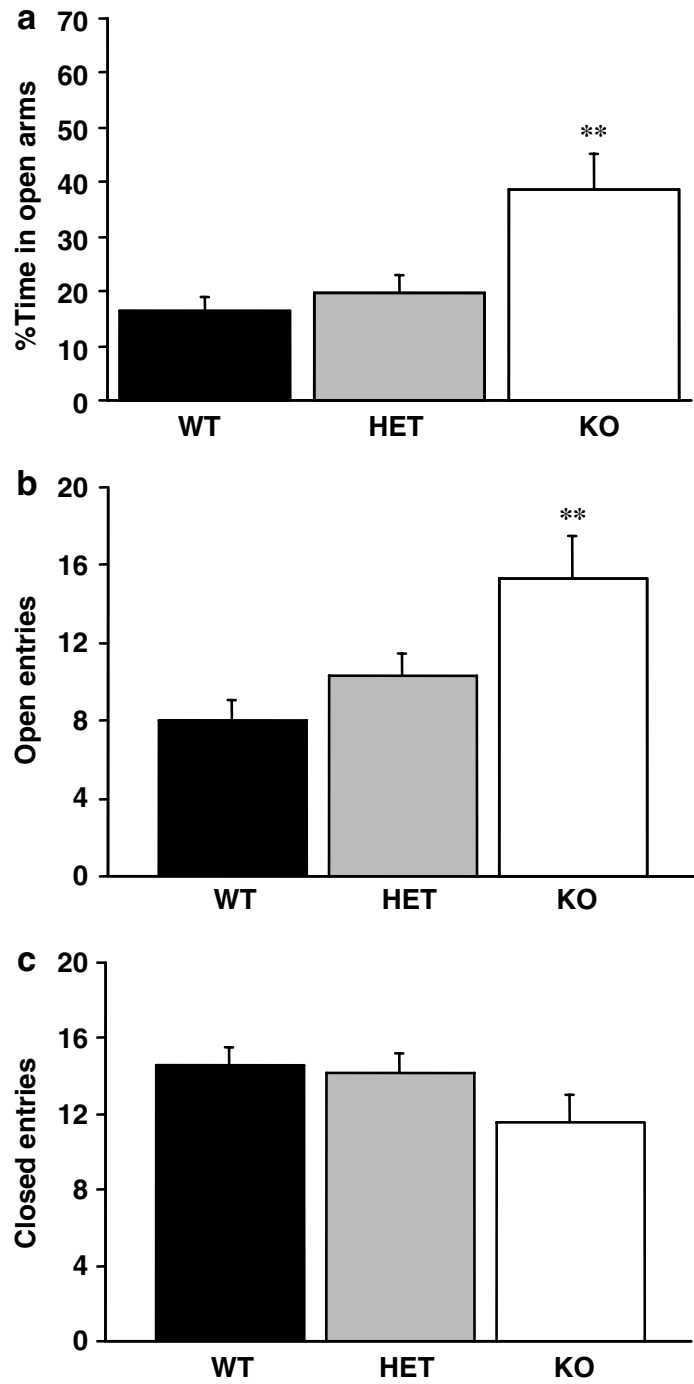

Figure I NR2A KO mice exhibit reduced anxiety-like behavior in the elevated plus-maze. NR2A KO mice spent more time (a) and made more entries (b) into the open arms, but made a similar number of entries into the closed arms (c), as compared to wild-type controls (WT) $(n=14-18 /$ genotype). ${ }^{*} * P<0.0$ I vs WT. Data in Figures $I-5$ are mean \pm SEM.

the session but were no different from WT controls by the final 5 min time bin. Overall, both NR2A KO and HET mice spent a significantly greater percentage of time in the center of the open field than WT controls (main effect of genotype: $\left.\mathrm{F}_{2,43}=5.19 ; P=0.01\right)$.

\section{Normal Locomotor Activity in a Familiar Open Field}

Altered open field locomotor activity in NR2A KO mice was dependent upon the novelty of the open field. Figure $4 \mathrm{a}$ shows that genotype differences in total distance traveled became successively lesser with repeated daily exposures to the open field, such that locomotor activity was no different between NR2A KO and WT by the fourth trial, while NR2A HET mice showed significantly less total distance traveled than WT and NR2A KO mice on trial 4 (main effect of genotype: $F_{2,100}=10.16, P<0.01$; main effect of day $\mathrm{F}_{4,100}=35.14, P<0.01$; genotype $\times$ day interaction: $\left.\mathrm{F}_{8,100}=2.81, P<0.01\right)$. In contrast, NR2A KO mice spent 

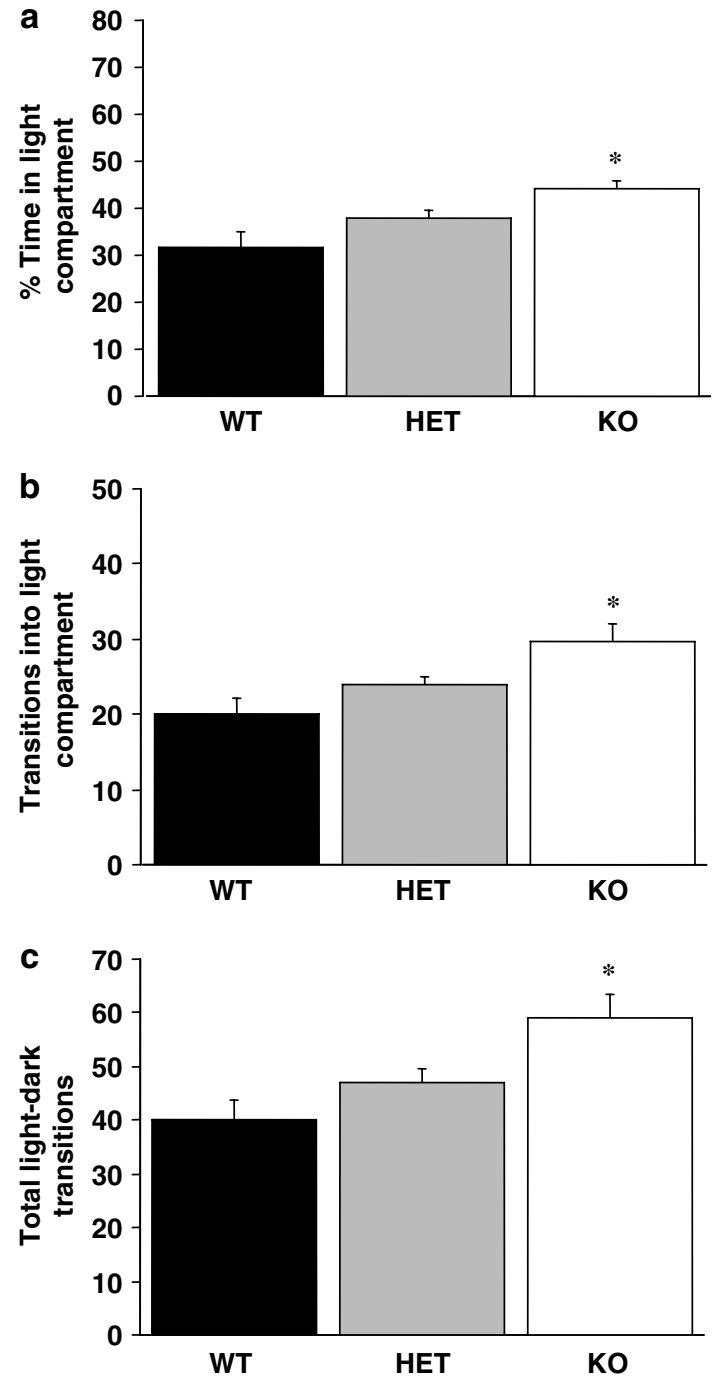

Figure 2 NR2A knockout (KO) mice exhibit reduced anxiety-like behavior in the light/dark exploration test. NR2A KO mice spent more time (a) and made more transitions (b) into the light compartment, and made more light-dark transitions overall (c), as compared to wild-type controls (WT) ( $n=14-\mid 8 /$ genotype). ${ }^{*} P<0.05$ vs WT.

a significantly greater percentage of time in the center of the open field than WT controls on trials, either when locomotor activity was different (trials 1-3) or no different (trial 4) between genotypes (main effect of genotype: $\mathrm{F}_{2,100}=7.50, P<0.01$; main effect of day: $\mathrm{F}_{4,100}=12.56$, $P<0.01$; genotype $\times$ day interaction: $\mathrm{F}_{8,100}=3.43, P<0.01$ ) (Figure $4 \mathrm{~b}$ ). NR2A HET showed significantly more center time than WT controls on the first trial.

\section{Normal Locomotor Activity in the Home Cage}

Consistent with the normal locomotor activity phenotype in NR2A KO mice in a familiar open field, there were no genotype differences in $24 \mathrm{~h}$ locomotor activity in the home cage (main effect of genotype: $P>0.05$ ) (Figure $4 \mathrm{c}$ ).

\section{Antidepressant-Like Phenotype in the Forced Swim Test}

There was a significant effect of genotype on behavior in the forced swim test for depression-related behavior. As shown
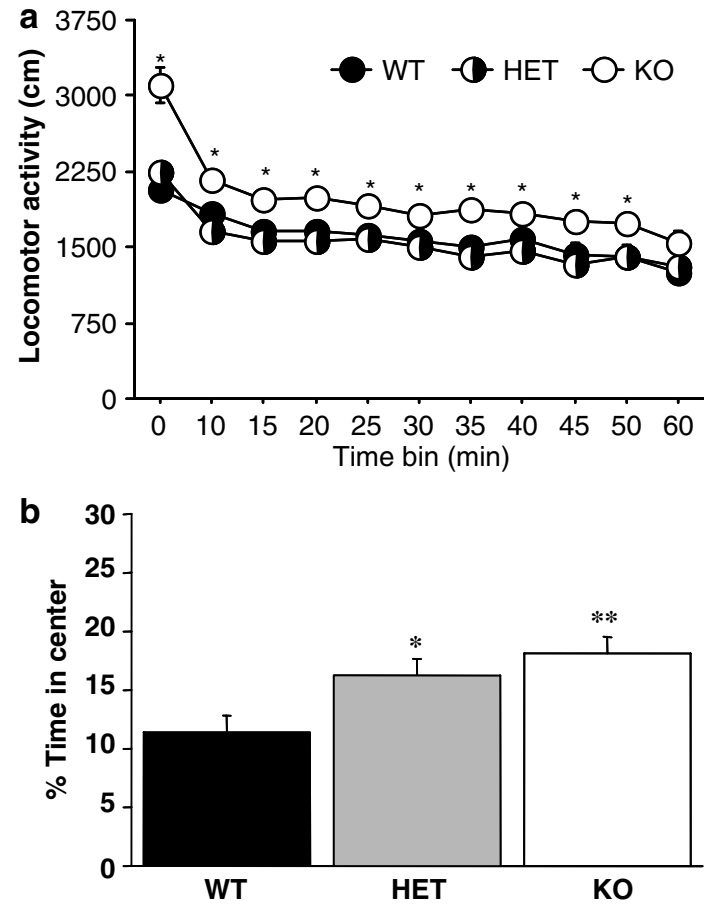

Figure 3 NR2A knockout $(\mathrm{KO})$ mice exhibit reduced anxiety-like behavior in the novel open field test. (a) NR2A KO mice showed higher levels of exploratory locomotion during initial exposure to a novel open field than wild-type controls (WT) ( $n=14-18 /$ genotype). (b) On average, NR2A KO mice spent more time in the center of the open field as compared to $W T$. *** $P<0.01$, * $P<0.05$ vs WT.

in Figure 5, NR2A KO, but not HET, mice showed significantly less immobility than WT controls in the forced swim test (main effect of genotype: $\mathrm{F}_{2.43}=4.02 ; P<0.01$ ).

\section{Antidepressant-Like Phenotype in the Tail Suspension Test}

Genotype significantly affected behavior in the tail suspension test for depression-related activity. NR2A KO, but not HET, mice showed significantly less immobility than WT controls in the tail suspension test (main effect of genotype: $\mathrm{F}_{2,42}=17.91 ; P<0.01$ ) (Figure 6).

\section{Normal Physical Health, Sensory and Neurological Functions}

As shown in Table 1, neither NR2A KO nor HET mice showed any gross behavioral abnormalities during exposure to an empty cage, with the exception that there was less defecation in both KO and HET mice than WT controls. All measures of physical health, and simple sensory and neurological functions were normal in NR2A KO and HET mice.

There were no genotype differences in the acoustic startle response (main effect of genotype: $P>0.05$ ). There was a significant effect of prepulse intensity $\left(F_{2,78}=90.68\right.$; $P<0.01)$, but not genotype $(P>0.05)$ and no prepulse intensity $\times$ genotype interaction $(P>0.05)$ on prepulse inhibition of the startle response. Data averaged across prepulse intensity are shown in Table 1. 

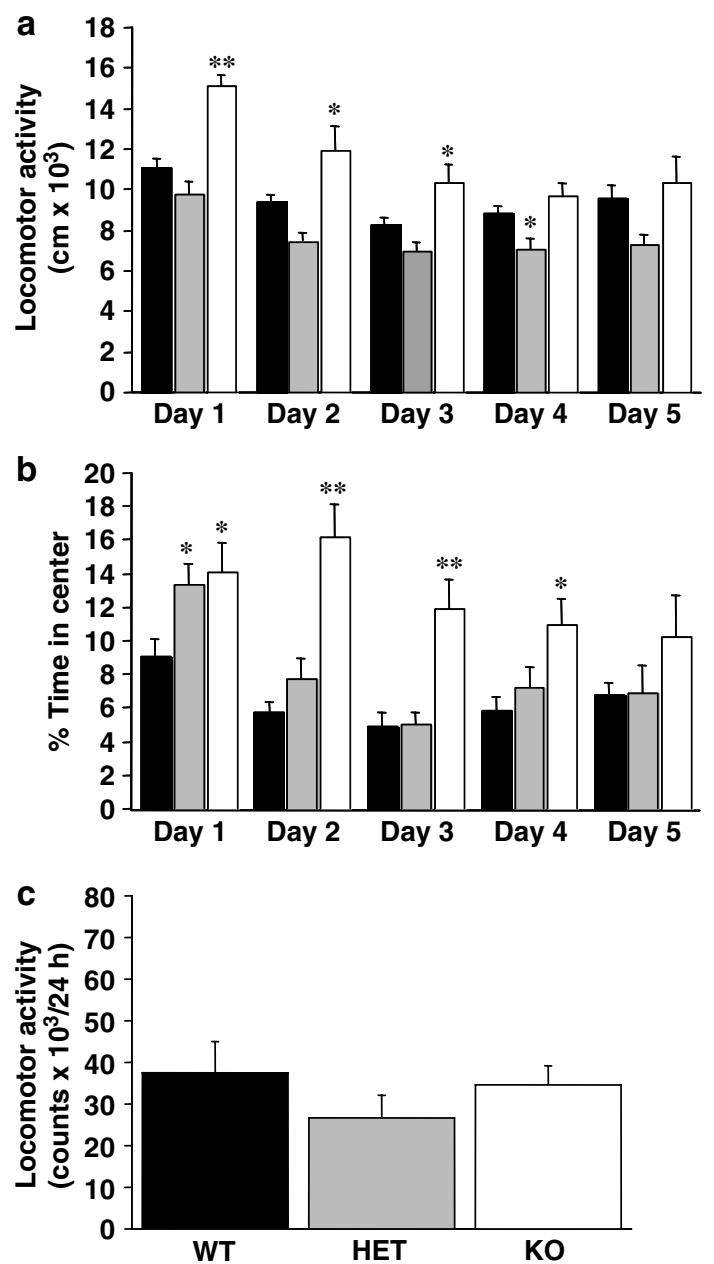

Figure 4 NR2A knockout (KO) mice show normal locomotor activity and reduced anxiety-like behavior in a familiar open field. (a) NR2A KO mice initially showed higher levels of locomotor activity in comparison to wild-type controls (WT), but do not differ from WT mice on days 4 and 5 . Black bars $=W T$, grey bars $=H E T$, white bars $=K O(n=8-1$ l/genotype $)$ (b) Overall, NR2A KO mice spent more time in the center of the open field in comparison to WT controls. Black circles $=W T$, grey circles $=H E T$, white circles $=K O \quad(n=8-1$ I/genotype). (c) NR2A KO mice showed normal levels of locomotor activity in the non-aversive environment of the home cage $\left(n=12\right.$ /genotype). ${ }^{*} * P<0.01$ vs $W T$, $* P<0.05$ vs WT.

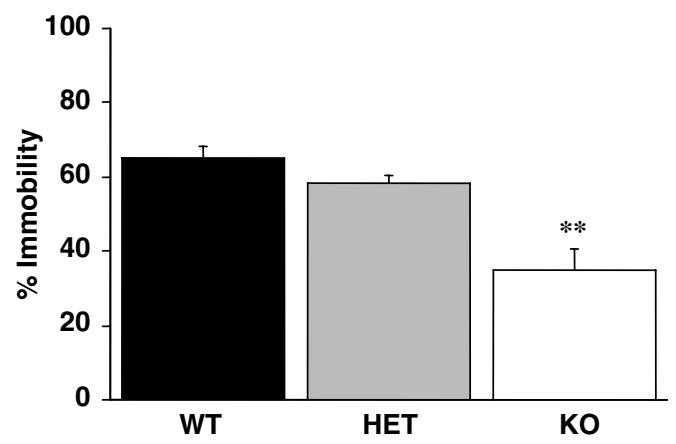

Figure 5 NR2A knockout (KO) mice exhibit reduced depressionrelated behavior in the forced swim test. NR2A KO mice showed less immobility than wild-type controls (WT) $(n=|3-| 8 /$ genotype). $* * P<0.01$ vs WT.

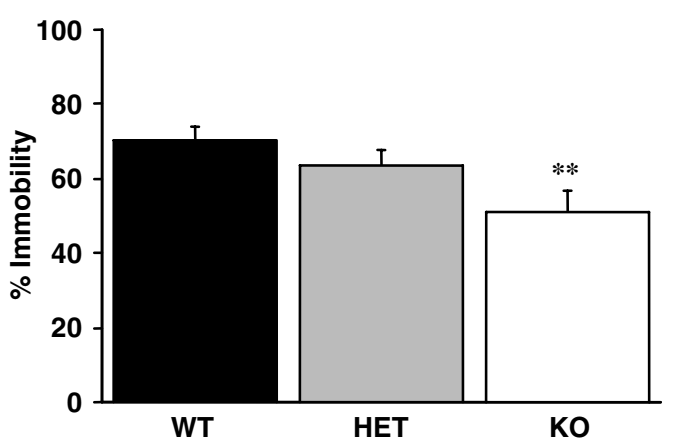

Figure 6 NR2A knockout (KO) mice exhibit reduced depressionrelated behavior in the tail suspension test. NR2A KO mice showed less immobility than wild-type controls (WT) $\left(n=|4-| 7 /\right.$ genotype). ${ }^{*} * P<0.0 \mid$ vs WT.

\section{DISCUSSION}

The present study provides some of the first evidence linking the NR2A subunit of the NMDA receptor to the regulation of emotional behavior. NR2A KO mice exhibited profiles consistent with a reduction in anxiety-like behavior in the elevated plus-maze, light/dark exploration test and novel open field. In addition, NR2A KO mice displayed phenotypic alterations in the forced swim test and tail suspension test that were consistent with a reduction in depression-related behavior. NR2A HET mice showed similar albeit modest and nonsignificant changes in these tests, with the exception of the novel open field, where these mice showed a significant anxiolytic-like increase in center time, relative to WT controls. The phenotypic consistency observed in NR2A KO mice across tests is impressive given evidence that the tasks employed measure partially distinct forms of anxiety- and depression-related behavior, as evidenced in part by the previous studies showing that certain mutant mouse lines display phenotypic abnormalities on some of these tasks but not others (for reviews see (Cryan et al, 2005; Holmes, 2001)). Thus, present data demonstrate a highly robust anxiolytic- and antidepressantlike phenotype in NR2A KO mice.

Alterations in motor, sensory, and neurological functions resulting from a gene mutation can lead to false positives and can confound performance on mouse tests for anxiety and depression employed in the preset study (Crawley, 2000; Holmes, 2001) (Holmes and Cryan, 2005). While NR2A KO mice exhibited greater levels of exploratory locomotor activity than WT controls in the novel open field, this difference occurred during the early part of the $60 \mathrm{~min}$ test, being especially prominent during the first $5 \mathrm{~min}$ and disappearing by the end of the test session. In a separate experiment, genotype differences in exploratory activity were abolished by repeated exposure to the open field, while NR2A KO mice continued to show greater center time than WT controls even when activity had habituated to WT levels.

Taken together, this pattern of behavior is suggestive of a reduced response to the anxiety-related component of the test rather than a nonspecific locomotor hyperactivity or an exaggerated response to novelty in the NR2A KO mouse; a finding consistent with data published previously (Miyamoto et al, 2001). Providing further support for this 
Table I NR2A (knockout) KO Mice Show Normal Empty Cage Behaviors, Physical Health, Sensory Reflexes, and Neurological Functions

\begin{tabular}{|c|c|c|c|}
\hline & WT & HET & $\mathrm{KO}$ \\
\hline \multicolumn{4}{|l|}{ Empty cage behaviors } \\
\hline Freezing & 7 & 0 & 0 \\
\hline Trembling & 0 & 0 & 0 \\
\hline Sniffing & 100 & 100 & 100 \\
\hline Licking & 0 & 0 & 0 \\
\hline Rearing & 100 & 94 & 93 \\
\hline Jumping & 0 & 0 & 0 \\
\hline Seizure & 0 & 0 & 0 \\
\hline Defecation & 71 & 22 & 14 \\
\hline Urination & 7 & । & 14 \\
\hline Head bobbing & 0 & 0 & 0 \\
\hline Circling & 0 & 0 & 0 \\
\hline Abnormal gait & 0 & 0 & 0 \\
\hline Retropulsion & 0 & 0 & 0 \\
\hline \multicolumn{4}{|l|}{ Physical health } \\
\hline Missing whiskers & 0 & 0 & 0 \\
\hline Bald patches & 0 & 0 & 0 \\
\hline Exophthalmus & 0 & 0 & 0 \\
\hline Straub tail & 0 & 0 & 0 \\
\hline Kinked tail & 0 & 0 & 0 \\
\hline Kyphosis & 0 & 0 & 0 \\
\hline Lordosis & 0 & 0 & 0 \\
\hline Body weight (g) & $23.4 \pm 0.9$ & $22.2 \pm 0.7$ & $20.8 \pm 0.9$ \\
\hline Core body temperature $\left({ }^{\circ} \mathrm{C}\right)$ & $38.1 \pm 0.2$ & $38.1 \pm 0.1$ & $38.1 \pm 0.1$ \\
\hline \multicolumn{4}{|l|}{ Sensory reflexes } \\
\hline Approach response & 100 & 100 & 100 \\
\hline Touch response & 100 & 100 & 100 \\
\hline Palpebral response & 100 & 100 & 100 \\
\hline Pinna reflex & 100 & 100 & 100 \\
\hline Tail pinch response & 100 & 100 & 100 \\
\hline Startle response (arbitrary units) & $221 \pm 41$ & $295 \pm 41$ & $371 \pm 47$ \\
\hline \%Prepulse inhibition of startle & $23.8 \pm 3.3$ & $25.0 \pm 2.9$ & $27.5 \pm 4.3$ \\
\hline \multicolumn{4}{|l|}{ Motor, neurological } \\
\hline Splayed limbs & 0 & 0 & 0 \\
\hline Forepaw clutch & 0 & 0 & 0 \\
\hline Hindpaw clutch & 0 & 0 & 7 \\
\hline
\end{tabular}

Fewer NR2A KO and HET mice defected during exposure to the empty cage. Data denote the percentage of animals showing a response unless specified otherwise in parenthesis. \% Prepulse inhibition of startle data is shown as an average over three prepulse intensities ( $n=12-18$ /genotype)

interpretation, NR2A KO mice exhibited normal levels of locomotor activity in the non-aversive context of the home cage. In addition, NR2A KO mice were found to be no different from WT controls on a range of measures for basic motor abilities, physical health and sensory and neurological functions. Interestingly, NR2A KO and HET mice defecated less than WT controls during brief exposure to an empty cage; providing another example of reduced emotional reactivity in these mice. Consistent with earlier findings, NR2A KO mice were also found to display normal prepulse inhibition of the acoustic startle response (Takeuchi et al, 2001). Thus, these data rule out the possibility that the presently observed emotion-related alterations in NR2A KO mice were an artifact of nonspecific behavioral or neurological abnormalities.

In contrast to these findings, an independently generated line of NR2A KO mice has been reported to show reductions in footshock-induced freezing, but normal behavior in the elevated plus-maze (although the only variable measured was open arm entries) (Moriya et al, 2000). Differences in procedural methodology as well as factors such as genetic background may have contributed to the differences between studies. Moriya et al (2000) studied NR2A KO mice on a $129 / \mathrm{SvJ} \times \mathrm{C} 57 \mathrm{BL} / 6 \times \mathrm{DBA} / 2 \times$ hybrid background, while a genome-wide scan of SNP markers confirmed that NR2A KO mice used in the present study were $>99 \%$ C57BL/6J congenic. The present study also controlled for the potential influence of parental behaviors and early life experience (Holmes et al, 2005; Meaney, 2001) by breeding all genotypes from NR2A HET $\times$ NR2A HET parents. Thus, it may be that differences in these variables influenced the expression of an anxiety-related phenotype in the NR2A KO mouse across the two studies.

Notwithstanding, the finding that NR2A KO mice exhibit reduced anxiety- and depression-related behavior is consistent with previous pharmacological studies in rats showing anxiolytic- and antidepressant-like effects of competitive NMDA receptor antagonists and noncompetitive channel blockers in the same tasks as presently employed, including the elevated plus-maze, tail suspension test and forced swim test (Kelly et al, 1997; Papp and Moryl, 1994; Silvestre et al, 1997; Trullas and Skolnick, 1990; Wiley et al, 1995). In addition, systemic administration of zinc, one of the effects of which is inhibition of NR2A-subunit containing NMDA receptors, and treatment with glycine partial agonists have also been shown to produce antidepressant-like effects in these tests (Kroczka et al, 2001; Nowak et al, 2003; Trullas et al, 1989; Trullas and Skolnick, 1990; Zheng et al, 2001).

Taken together with present data, these results provide converging lines of evidence supporting anxiolytic- and antidepressant-like effects of inactivation of NR2A subunit containing NMDA receptors. However, the neural mechanisms underlying these effects remain to be determined. NR2A subunit-containing NMDA receptors are highly expressed in forebrain regions mediating emotion, such as the hippocampus and amygdala (Law et al, 2003; Magnusson et al, 2002; Sah and Lopez De Armentia, 2003). A simple model would predict that blockade of glutamatergic excitation of the neuronal activity in regions such as the amygdala would reduce emotional reactivity. However, emotional behavior is mediated by multiple neurotransmitter systems and the role of NMDA receptors in these behaviors is more likely to result from complex interactions with other systems (Paul and Skolnick, 2003). Of note in this context, NR2A KO mice have increased dopamine and serotonin metabolism in the frontal cortex, and decreased norepinephrine metabolism in the hippocampus (Miyamoto 
et al, 2001). Although more direct measures of monoamine activity in these regions, such as extracellular fluid levels, have not been made, the possibility of altered monoamine function in NR2A KO mice is interesting given the longstanding hypothesis linking monoamines to emotional behavior (Charney, 1998).

Further studies are also needed to determine the precise nature of monoamine changes in NR2A KO mice and the possible contribution of these alterations to their anxiolyticand antidepressant-like phenotype. Interestingly, however, previous studies have shown that NMDA receptor antagonists can block the antidepressant-like effects of monoamine-targeted drugs such as imipramine (Meloni et al, 1993). In addition, chronic treatment with monoaminergic antidepressants has been shown to antagonize and desensitize NMDA receptor function (Mjellem et al, 1993; Reynolds and Miller, 1988). Moreover, antidepressant effects of NMDA receptor antagonists, such as D-cycloserine, amantadine and ketamine have been reported in clinical populations (Berman et al, 2000; Crane, 1959; Vale et al, 1971). Thus, activity at NMDA receptors may contribute to the mechanism of action of the most commonly used pharmacotherapies for mood and anxiety disorders.

One implication of these findings, together with the present data, is that targeting NMDA receptors, and specifically the NR2A subunit, with selective antagonists could have efficacy as first-line or adjunct treatment for emotional disorders. Past experience has shown that the use of nonspecific NMDA receptor antagonists such as MK-801 and ketamine in neuropsychiatric disorders may be limited by their adverse side-effect profile (Javitt, 2004; Krystal et al, 1999). Blocking NMDA receptor function across brain regions would be predicted to cause general depression of the central nervous system (CNS), as well as produce specific impairments in cognition and possibly psychosis in certain at-risk individuals given the known role of the NMDA receptor in these behaviors (Goff and Coyle, 2001; Nakazawa et al, 2004). As the NR2A subunit clearly is part of a large population of mature NMDA receptors, it would seem unlikely that specifically targeting NR2A would circumvent all of these effects. Indeed, NR2A KO mice exhibit deficits in certain forms of synaptic plasticity and learning and memory performance, as well as hypersensitivity to behavioral effects of antipsychotics (Kishimoto et al, 2001; Kiyama et al, 1998; Miyamoto et al, 2001; Sakimura et al, 1995). There is also a caveat to basing the conclusion that targeting the NR2A will affect emotional behaviors solely on phenotypic data in the $\mathrm{KO}$ mouse. Inactivation of the NR2A subunit during development has the potential to indirectly cause abnormalities in NMDA receptor function, for example, via changes in other NR2 subunits, and these abnormalities could contribute to the emotional phenotype in NR2A KO mice. Of note in this context, however, there is no evidence of developmental alterations in the NR2B subunit in the NR2A KO mice (Townsend et al, 2003). Nor are there clear and consistent emotion-related effects of NR2B subunit antagonists in rodent tests (Dere et al, 2003; Fraser et al, 1996; Sanger and Jackson, 1989).

Notwithstanding, an important question for future studies will be to examine the anxiolytic- and antidepressant-like effects, as well the more general behavioral profile, of drugs that can selectively block NR2A subunit function. These studies will also speak to the potential role of other NMDA receptor subunits in modulating emotional behavior, which is not ruled out by the present findings. To-date, however, the specificity of putative NR2A-selective antagonists remains somewhat controversial with little research of their antagonistic efficacy in brain following systemic treatment (Berberich et al, 2005; Liu et al, 2004a; Weitlauf et al, 2005).

In summary, the results of the present study demonstrate decreased anxiety- and depression-related behavior in NR2A KO mice on multiple tasks. This emotion-related phenotype was not due to more general deficits in locomotor activity or gross abnormalities in sensory or neurological functions. Anxiolytic- and antidepressant-like effects of NR2A gene inactivation are consistent with the effects of NMDA antagonists in rodent models and provide further insight into the molecular mechanisms underlying emotion and the pathophysiology and treatment of mood and anxiety disorders.

\section{ACKNOWLEDGEMENTS}

We thank Dr Masayoshi Mishina for providing the breeding stocks used for these studies, Dr David Lovinger for helpful comments on an earlier version of the manuscript, and Michael Feyder for technical assistance. Research supported by the National Institute on Alcohol Abuse and Alcoholism Research Program and National Alliance for Research on Schizophrenia and Depression grant to $\mathrm{AH}$.

\section{REFERENCES}

Auer DP, Putz B, Kraft E, Lipinski B, Schill J, Holsboer F (2000). Reduced glutamate in the anterior cingulate cortex in depression: an in vivo proton magnetic resonance spectroscopy study. Biol Psychiatry 47: 305-313.

Bartanusz V, Aubry JM, Pagliusi S, Jezova D, Baffi J, Kiss JZ (1995). Stress-induced changes in messenger RNA levels of $N$-methyl-Daspartate and AMPA receptor subunits in selected regions of the rat hippocampus and hypothalamus. Neuroscience 66: 247-252.

Berberich S, Punnakkal P, Jensen V, Pawlak V, Seeburg PH, Hvalby $\mathrm{O}$ et al (2005). Lack of NMDA receptor subtype selectivity for hippocampal long-term potentiation. J Neurosci 25: 6907-6910.

Berman RM, Cappiello A, Anand A, Oren DA, Heninger GR, Charney DS et al (2000). Antidepressant effects of ketamine in depressed patients. Biol Psychiatry 47: 351-354.

Boyce-Rustay JM, Holmes A (2005). Functional roles of NMDA receptor NR2A and NR2B subunits in the acute intoxicating effects of ethanol in mice. Synapse 56: 222-225.

Charney DS (1998). Monoamine dysfunction and the pathophysiology and treatment of depression. J Clin Psychiatry 59(Suppl 14): 11-14.

Crane GE (1959). Cyloserine as an antidepressant agent. Am J Psychiatry 115: 1025-1026.

Crawley JN (1981). Neuropharmacologic specificity of a simple animal model for the behavioral actions of benzodiazepines. Pharmacol Biochem Behav 15: 695-699.

Crawley JN (2000). What's Wrong With My Mouse? Behavioral Phenotyping of Transgenic and Knockout Mice. Wiley-Liss: New York.

Crawley JN, Paylor R (1997). A proposed test battery and constellations of specific behavioral paradigms to investigate the behavioral phenotypes of transgenic and knockout mice. Horm Behav 31: 197-211. 
Cryan JF, Mombereau C, Vassout A (2005). The tail suspension test as a model for assessing antidepressant activity: review of pharmacological and genetic studies in mice. Neurosci Biobehav Rev 29: 571-625.

Cull-Candy S, Brickley S, Farrant M (2001). NMDA receptor subunits: diversity, development and disease. Curr Opin Neurobiol 11: 327-335.

Dere E, Topic B, De Souza Silva MA, Fink H, Buddenberg T, Huston JP (2003). NMDA-receptor antagonism via dextromethorphan and ifenprodil modulates graded anxiety test performance of C57BL/6 mice. Behav Pharmacol 14: 245-249.

Fitzgerald LW, Ortiz J, Hamedani AG, Nestler EJ (1996). Drugs of abuse and stress increase the expression of GluR1 and NMDAR1 glutamate receptor subunits in the rat ventral tegmental area: common adaptations among cross-sensitizing agents. J Neurosci 16: 274-282.

Fraser CM, Cooke MJ, Fisher A, Thompson ID, Stone TW (1996). Interactions between ifenprodil and dizocilpine on mouse behaviour in models of anxiety and working memory. Eur Neuropsychopharmacol 6: 311-316.

Goff DC, Coyle JT (2001). The emerging role of glutamate in the pathophysiology and treatment of schizophrenia. Am J Psychiatry 158: 1367-1377.

Handley SL, Mithani S (1984). Effects of alpha-adrenoceptor agonists and antagonists in a maze-exploration model of 'fear'motivated behaviour. Naunyn Schmiedebergs Arch Pharmacol 327: $1-5$.

Holemans S, De Paermentier F, Horton RW, Crompton MR, Katona CL, Maloteaux JM (1993). NMDA glutamatergic receptors, labelled with $[3 \mathrm{H}] \mathrm{MK}-801$, in brain samples from drug-free depressed suicides. Brain Res 616: 138-143.

Holmes A (2001). Targeted gene mutation approaches to the study of anxiety-like behavior in mice. Neurosci Biobehav Rev 25: 261-273.

Holmes A, Cryan JF (2005). The ascent of mouse: advances in modeling human depression and anxiety. Nat Rev Drug Discov 4: 775-790.

Holmes A, Hollon TR, Gleason TC, Liu Z, Dreiling J, Sibley DR et al (2001). Behavioral characterization of dopamine D5 receptor null mutant mice. Behav Neurosci 115: 1129-1144.

Holmes A, Kinney JW, Wrenn CC, Li Q, Yang RJ, Ma L et al (2003a). Galanin GAL-R1 receptor null mutant mice display increased anxiety-like behavior specific to the elevated plusmaze. Neuropsychopharmacology 28: 1031-1044.

Holmes A, le Guisquet AM, Vogel E, Millstein RA, Leman S, Belzung C (2005). Early life genetic, epigenetic and environmental factors shaping emotionality in rodents. Neurosci Biobehav Rev 29: 1335-1346.

Holmes A, Murphy DL, Crawley JN (2002a). Reduced aggression in mice lacking the serotonin transporter. Psychopharmacology (Berlin) 161: 160-167.

Holmes A, Murphy DL, Crawley JN (2003b). Abnormal behavioral phenotypes of serotonin transporter knockout mice: parallels with human anxiety and depression. Biol Psychiatry 54: 953-959.

Holmes A, Yang RJ, Lesch KP, Crawley JN, Murphy DL (2003c). Mice lacking the serotonin transporter exhibit 5-HT(1A) receptor-mediated abnormalities in tests for anxiety-like behavior. Neuropsychopharmacology 28: 2077-2088.

Holmes A, Yang RJ, Murphy DL, Crawley JN (2002b). Evaluation of antidepressant-related behavioral responses in mice lacking the serotonin transporter. Neuropsychopharmacology 27: 914-923.

Javitt DC (2004). Glutamate as a therapeutic target in psychiatric disorders. Mol Psychiatry 9: 984-997, 979.

Kelly JP, Wrynn AS, Leonard BE (1997). The olfactory bulbectomized rat as a model of depression: an update. Pharmacol Ther 74: 299-316.

Kishimoto Y, Kawahara S, Mori H, Mishina M, Kirino Y (2001). Long-trace interval eyeblink conditioning is impaired in mutant mice lacking the NMDA receptor subunit epsilon 1. Eur J Neurosci 13: 1221-1227.

Kiyama Y, Manabe T, Sakimura K, Kawakami F, Mori H, Mishina M (1998). Increased thresholds for long-term potentiation and contextual learning in mice lacking the NMDA-type glutamate receptor epsilon1 subunit. J Neurosci 18: 6704-6712.

Kroczka B, Branski P, Palucha A, Pilc A, Nowak G (2001). Antidepressant-like properties of zinc in rodent forced swim test. Brain Res Bull 55: 297-300.

Krystal JH, D'Souza DC, Petrakis IL, Belger A, Berman RM, Charney DS et al (1999). NMDA agonists and antagonists as probes of glutamatergic dysfunction and pharmacotherapies in neuropsychiatric disorders. Harv Rev Psychiatry 7: 125-143.

Laube B, Kuhse J, Betz H (1998). Evidence for a tetrameric structure of recombinant NMDA receptors. J Neurosci 18: 2954-2961.

Law AJ, Deakin JF (2001). Asymmetrical reductions of hippocampal NMDAR1 glutamate receptor mRNA in the psychoses. Neuroreport 12: 2971-2974.

Law AJ, Weickert CS, Webster MJ, Herman MM, Kleinman JE, Harrison PJ (2003). Expression of NMDA receptor NR1, NR2A and NR2B subunit mRNAs during development of the human hippocampal formation. Eur J Neurosci 18: 1197-1205.

Liu L, Wong TP, Pozza MF, Lingenhoehl K, Wang Y, Sheng M et al (2004a). Role of NMDA receptor subtypes in governing the direction of hippocampal synaptic plasticity. Science 304: $1021-1024$.

Liu XB, Murray KD, Jones EG (2004b). Switching of NMDA receptor $2 \mathrm{~A}$ and $2 \mathrm{~B}$ subunits at thalamic and cortical synapses during early postnatal development. J Neurosci 24: 8885-8895.

Magnusson KR, Nelson SE, Young AB (2002). Age-related changes in the protein expression of subunits of the NMDA receptor. Brain Res Mol Brain Res 99: 40-45.

Martinez G, Ropero C, Funes A, Flores E, Blotta C, Landa AI et al (2002). Effects of selective NMDA and non-NMDA blockade in the nucleus accumbens on the plus-maze test. Physiol Behav 76: 219-224.

Meador-Woodruff JH, Hogg Jr AJ, Smith RE (2001). Striatal ionotropic glutamate receptor expression in schizophrenia, bipolar disorder, and major depressive disorder. Brain Res Bull 55: 631-640.

Meaney MJ (2001). Maternal care, gene expression, and the transmission of individual differences in stress reactivity across generations. Annu Rev Neurosci 24: 1161-1192.

Meloni D, Gambarana C, De Montis MG, Dal Pra P, Taddei I, Tagliamonte A (1993). Dizocilpine antagonizes the effect of chronic imipramine on learned helplessness in rats. Pharmacol Biochem Behav 46: 423-426.

Miyamoto Y, Yamada K, Noda Y, Mori H, Mishina M, Nabeshima $\mathrm{T}$ (2001). Hyperfunction of dopaminergic and serotonergic neuronal systems in mice lacking the NMDA receptor epsilon1 subunit. J Neurosci 21: 750-757.

Mjellem N, Lund A, Hole K (1993). Reduction of NMDA-induced behaviour after acute and chronic administration of desipramine in mice. Neuropharmacology 32: 591-595.

Moghaddam B (1993). Stress preferentially increases extraneuronal levels of excitatory amino acids in the prefrontal cortex: comparison to hippocampus and basal ganglia. J Neurochem 60: $1650-1657$.

Moghaddam B, Bolinao ML, Stein-Behrens B, Sapolsky R (1994). Glucocorticoids mediate the stress-induced extracellular accumulation of glutamate. Brain Res 655: 251-254.

Molchanov ML, Guimaraes FS (2002). Anxiolytic-like effects of AP7 injected into the dorsolateral or ventrolateral columns of the periaqueductal gray of rats. Psychopharmacology (Berlin) 160: $30-38$.

Moriya T, Kouzu Y, Shibata S, Kadotani H, Fukunaga K, Miyamoto $\mathrm{E}$ et al (2000). Close linkage between calcium/calmodulin kinase II alpha/beta and NMDA-2A receptors in the lateral amygdala 
and significance for retrieval of auditory fear conditioning. Eur J Neurosci 12: 3307-3314.

Nakazawa K, McHugh TJ, Wilson MA, Tonegawa S (2004). NMDA receptors, place cells and hippocampal spatial memory. Nat Rev Neurosci 5: 361-372.

Nowak G, Ordway GA, Paul IA (1995). Alterations in the N-methyl$\mathrm{D}$-aspartate (NMDA) receptor complex in the frontal cortex of suicide victims. Brain Res 675: 157-164.

Nowak G, Szewczyk B, Wieronska JM, Branski P, Palucha A, Pilc A et al (2003). Antidepressant-like effects of acute and chronic treatment with zinc in forced swim test and olfactory bulbectomy model in rats. Brain Res Bull 61: 159-164.

Palmer AM, Burns MA, Arango V, Mann JJ (1994). Similar effects of glycine, zinc and an oxidizing agent on [3H]dizocilpine binding to the $N$-methyl-D-aspartate receptor in neocortical tissue from suicide victims and controls. J Neural Transm Gen Sect 96: 1-8.

Papp M, Moryl E (1994). Antidepressant activity of noncompetitive and competitive NMDA receptor antagonists in a chronic mild stress model of depression. Eur J Pharmacol 263: 1-7.

Paul IA, Skolnick P (2003). Glutamate and depression: clinical and preclinical studies. Ann NY Acad Sci 1003: 250-272.

Pfleiderer B, Michael N, Erfurth A, Ohrmann P, Hohmann U, Wolgast $M$ et al (2003). Effective electroconvulsive therapy reverses glutamate/glutamine deficit in the left anterior cingulum of unipolar depressed patients. Psychiatry Res 122: 185-192.

Porsolt RD, Bertin A, Jalfre M (1978). 'Behavioural despair' in rats and mice: strain differences and the effects of imipramine. Eur $J$ Pharmacol 51: 291-294.

Przegalinski E, Tatarczynska E, Chojnacka-Wojcik E (2000). The influence of the benzodiazepine receptor antagonist flumazenil on the anxiolytic-like effects of CGP 37849 and ACPC in rats. Neuropharmacology 39: 1858-1864.

Reynolds IJ, Miller RJ (1988). Tricyclic antidepressants block N-methyl-D-aspartate receptors: similarities to the action of zinc. Br J Pharmacol 95: 95-102.

Rosenmund C, Stern-Bach Y, Stevens CF (1998). The tetrameric structure of a glutamate receptor channel. Science 280: 15961599.

Sah P, Lopez De Armentia M (2003). Excitatory synaptic transmission in the lateral and central amygdala. Ann NY Acad Sci 985: 67-77.

Sakimura K, Kutsuwada T, Ito I, Manabe T, Takayama C, Kushiya E et al (1995). Reduced hippocampal LTP and spatial learning in mice lacking NMDA receptor epsilon 1 subunit. Nature 373: 151-155.

Sanger DJ, Jackson A (1989). Effects of phencyclidine and other $\mathrm{N}$-methyl-D-aspartate antagonists on the schedule-controlled behavior of rats. J Pharmacol Exp Ther 248: 1215-1221.

Schorge S, Colquhoun D (2003). Studies of NMDA receptor function and stoichiometry with truncated and tandem subunits. J Neurosci 23: 1151-1158.

Silvestre JS, Nadal R, Pallares M, Ferre N (1997). Acute effects of ketamine in the holeboard, the elevated-plus maze, and the social interaction test in Wistar rats. Depress Anxiety 5: 29-33.
Singewald N, Zhou GY, Chen F, Philippu A (1996). Corticotropinreleasing factor modulates basal and stress-induced excitatory amino acid release in the locus coeruleus of conscious rats. Neurosci Lett 204: 45-48.

Singewald N, Zhou GY, Schneider C (1995). Release of excitatory and inhibitory amino acids from the locus coeruleus of conscious rats by cardiovascular stimuli and various forms of acute stress. Brain Res 704: 42-50.

Spooren W, Gasparini F (2004). mGlu5 receptor antagonists: a novel class of anxiolytics? Drug News Perspect 17: 251-257.

Steru L, Chermat R, Thierry B, Simon P (1985). The tail suspension test: a new method for screening antidepressants in mice. Psychopharmacology (Berlin) 85: 367-370.

Swanson CJ, Bures M, Johnson MP, Linden AM, Monn JA, Schoepp DD (2005). Metabotropic glutamate receptors as novel targets for anxiety and stress disorders. Nat Rev Drug Discov 4: 131-144.

Takeuchi T, Kiyama Y, Nakamura K, Tsujita M, Matsuda I, Mori H et al (2001). Roles of the glutamate receptor epsilon2 and delta2 subunits in the potentiation and prepulse inhibition of the acoustic startle reflex. Eur J Neurosci 14: 153-160.

Tang YP, Shimizu E, Dube GR, Rampon C, Kerchner GA, Zhuo M et al (1999). Genetic enhancement of learning and memory in mice. Nature 401: 63-69.

Townsend M, Yoshii A, Mishina M, Constantine-Paton M (2003). Developmental loss of miniature $N$-methyl-D-aspartate receptor currents in NR2A knockout mice. Proc Natl Acad Sci USA 100: $1340-1345$.

Trullas R, Jackson B, Skolnick P (1989). Anxiolytic properties of 1-aminocyclopropanecarboxylic acid, a ligand at strychnineinsensitive glycine receptors. Pharmacol Biochem Behav 34: 313-316.

Trullas R, Skolnick P (1990). Functional antagonists at the NMDA receptor complex exhibit antidepressant actions. Eur J Pharmacol 185: 1-10.

Tsien JZ, Huerta PT, Tonegawa S (1996). The essential role of hippocampal CA1 NMDA receptor-dependent synaptic plasticity in spatial memory. Cell 87: 1327-1338.

Vale S, Espejel MA, Dominguez JC (1971). Amantadine in depression. Lancet 2: 437.

Watanabe M, Inoue Y, Sakimura K, Mishina M (1993). Distinct distributions of five $N$-methyl-D-aspartate receptor channel subunit mRNAs in the forebrain. J Comp Neurol 338: 377-390.

Weitlauf C, Honse Y, Auberson YP, Mishina M, Lovinger DM, Winder DG (2005). Activation of NR2A-containing NMDA receptors is not obligatory for NMDA receptor-dependent long-term potentiation. J Neurosci 25: 8386-8390.

Wiley JL, Cristello AF, Balster RL (1995). Effects of site-selective NMDA receptor antagonists in an elevated plus-maze model of anxiety in mice. Eur J Pharmacol 294: 101-107.

Zheng F, Erreger K, Low CM, Banke T, Lee CJ, Conn PJ et al (2001). Allosteric interaction between the amino terminal domain and the ligand binding domain of NR2A. Nat Neurosci 4: 894-901. 